\title{
COMPETITION AND DOMINANCE OF INCOMPATIBILITY ALLELES IN DIPLOID POLLEN
}

\author{
By D. LEWIS \\ John Innes Horticultural Institution, London
}

Received I.i.47

\section{THE VALUE OF UNSELECTED GENES}

THE study of gene action has been obscured in the past by a difficulty of separating primary from secondary effects of the gene. Experimental work of Muller, Harland and others, and theoretical work of Fisher, Haldane and Wright have shown the great importance of the genetic environment in the expression and interaction of genes. Selection has generally favoured the wild-type allele in such a way that it has a large margin of safety in expression. In contrast, mutant alleles usually have a very slight and negative effect when in the presence of the wild-type allele. Thus the differences between the primary effects of alleles are masked by the damping action of the genotype.

The gene which determines incompatibility in higher plants does not suffer from this disadvantage. The genetic environment has certainly been selected in respect of this gene, but it has been selected in a direction such that each new mutant allele will have its maximum and independent expression, since all the alleles are a necessary part of the normal genetics of the population. Furthermore, we can put this gene into a new genetic environment. One of its main effects occurs in the haploid pollen grain, and thus in a diploid pollen of artificially produced tetraploids we have an entirely new condition which allows interaction between two alleles. Therefore, whatever interactions are found in such an environment, whether dominance or any new effects, they are primary properties of the gene.

Another restriction with most genes is that only a limited number of alleles can be differentiated by the usual phenotypic tests. Again this is mainly due to the buffering effect of the selected environment. In this respect also the incompatibility gene is exceptional, since each allele produces its highly specific and positive effect for which a decisive test is available. Very large numbers of alleles are known, so large in fact that it is probable that each act of mutation produces a unique allele.

The large number of alleles with their neomorphic effects, and the new environment of diploid pollen make this gene one of the most amenable to analysis and the most valuable for experimental genetics. 


\section{INCOMPATIBILITY IN TETRAPLOIDS}

Over a wide range of diploid species of plants, incompatibility conforms rigorously to one or other of two genetic systems. There is either the polyallelic system of plants without heterostyly or the diallelic system of heterostyled plants. It is only by a delicate balance between the main control genes and the background genes or polygenes that either kind of incompatibility can be efficiently maintained.

Changes in genetic balance, resulting as they do in a change in the degree of incompatibility, can be effected by keeping the main control genes constant and altering the background. This can be done in two ways, either by intra-specific selection or by inter-specific hybridisation (Mather and de Winton, I94I; Mather, I943). Alternatively changes of balance can be obtained by keeping the background genes constant and altering the main control gene. This again can be done in two ways, either by selecting a mutation to a self-compatible allele in a diploid (Williams and Silow, 1933), or by creating new interactions between the main control genes as a result of chromosome doubling in an autotetraploid.

As early as 1923 Crane had shown that the diploid Prunus avium was self-incompatible and the tetraploid Prunus cerasus was selfcompatible. A similar difference was found within a species by Gairdner ( 1926 ) between the diploid and tetraploid types of Campanula persicifolia, and in 1928 Darlington generalised these facts by pointing out "that tetraploidy seems to remove the absolute bar to selffertility" since "in the tetraplcid single inhibitors of pollen-tube growth cannot be expected to be absolute in effect." Evidence for the wider application of this generalisation came from the examination of incompatibility in natural diploid and polyploid forms of Allium schoenoprasum by Levan in 1936 and of Tulipa species by Upcott and Philp in I 939 .

It was not until spontaneous chromosome doubling in the Pyrus communis variety "Fertility" occurred, and tetraploids in other species were produced by colchicine, that a strict comparison could be made between a diploid and its autotetraploid. In Pyrus communis variety Fertility autotetraploidy brought about self-compatibility (Crane and Thomas, I939; Crane and Lewis, 1942). This effect was found to be due mainly to the doubled condition in the pollen grain since Fertility $2 x \times 4 x$ was compatible but the $4 x \times 2 x$ combination was not; and as a result of finding both compatible and incompatible pollen tubes in the tetraploid style after selfing and in the diploid style after pollinating with the tetraploid, a hypothesis was formulated that pollen grains with two different $\mathbf{S}$ alleles are compatible in a style carrying these alleles. It was shown that this is due to competition between different alleles in the pollen grains (Lewis and Modlibowska, I942). Pollen grains with such different alleles are described as heterogenic. 
In three species of Solanum also, tetraploidy completely removed the bar to self-fertilisation (Livermore and Johnstone, I939). In Petunia axillaris, Stout and Chandler (I94I) showed that the tetraploid was self-compatible, the $2 x \times 4^{x}$ cross was compatible (seed of this cross was later found to be inviable, but this is presumably due to sterility and not incompatibility), and the $4 x \times 2 x$ cross was incompatible. This situation is very similar to that in Pyrus, and further work (Stout and Chandler, I942) supported the hypothesis of allelic competition in the heterogenic pollen grain. The authors, however, did not point out the significance of their results. They found that the offspring from the tetraploid Petunia selfed were :

I. All self-compatible.

2. All inter-compatible.

3. All were incompatible when crossed as females with their diploid parental types.

4. All were compatible when crossed as males with their diploid parental type.

These facts prove that the offspring were all heterozygous for $\mathbf{S}$ alleles, because if homozygous plants were present, then half the pollen from the diploid parent should be compatible on one type of homozygous tetraploid and the other half of the pollen should be compatible on the other type of homozygous plants. Since all were incompatible when crossed as females with their diploid parental type there can have been no homozygous plants among the progeny.

This principle also explains the self- and inter-compatibility of all the progeny. On the competition hypothesis only heterogenic pollen would function on selfing a tetraploid, and this would ensure the S-heterozygosity that was found in all the offspring. In all, 2 I 3 plants were tested and this number is statistically adequate, since with a 17 : I ratio of heterozygotes to homozygotes based on random functioning of gametes, $\chi^{2}=12 \cdot 49$. This is nearly twice the value of $\chi^{2}$ at oI probability.

Further evidence came from tetraploid Oenothera organensis (Lewis, I 943a). In this plant, as presumably in Oe. raimannia (Hecht, I944), the effects of tetraploidy were not sufficient to overcome incompatibility entirely, but there was a great reduction of the incompatibility reaction as shown by the growth of the pollen tubes. Although they failed to achieve fertilisation, they grew to the base of the style $160 \mathrm{~mm}$. long in 24 hours as in the compatible crosses. Here again this effect occurred in the tetraploid when selfed, and, within the same genotype, in the $2 x \times 4 x$ but not in the reciprocal cross.

But further work showed that there were exceptions to this generalisation for certain genotypes. Thus, while genotypes $\mathbf{S}_{3 \cdot 3.6 .6}$, $\mathbf{S}_{3.3 .4 .4}$ and $\mathbf{S}_{3.4 .6 .6}$ had the reduced incompatibility reaction and produced long tubes, the genotype $\mathbf{S}_{4.4 .6 .6}$ did not show this effect. Evidently the pollen genotypes $\mathbf{S}_{4.4}, \mathbf{S}_{4} .6$ and $\mathbf{S} 6.6$ did not have a 
reduced reaction, and by eliminating these genotypes from those produced by the $\mathbf{S}_{3.4 .6 .6}$ plant, it was concluded that the heterogenic pollen grains $\mathbf{S}_{3.4}$ and $\mathbf{S}_{3} .6$ were those with a reduced incompatibility reaction.

Differentiation in the capacity for interaction appeared in the style as well as in the pollen. Some types of heterogenic pollen were fully compatible on a style carrying one only of the alleles present in the pollen, but were incompatible on styles carrying the other allele only. For example, $\mathbf{S}_{3.4}$ pollen on an $\mathbf{S}_{4.4 .6 .6}$ style produced seed, but on $\mathbf{S}_{3.3 .6 .6}$ styles it failed to do so. Thus partial dominance of one allele over another in the pollen grain, as well as other interactions, is present in some combinations.

The effect of dominance was foreshadowed by the explanation of reciprocal differences in Prunus domestica by Crane and Lawrence (1929). Thus "In polyploid plants exhibiting incompatibility the gametes will carry more than one factor for incompatibility, and the possibility of the occurrence of interaction favourable to greater variation in pollen-tube growth must be considered. For example, two tetraploid plants of the constitution Si.r.2.3 and SI.I.2.2 might present different inhibitory effects to $\mathbf{S} 2.3$ pollen." This effect was also used by Lawrence (1930) in his interpretation of incompatibility in Verbascum. He regarded it to be caused by the unlike allele $\left(\mathbf{S}_{3}\right)$ positively promoting pollen-tube growth.

An alternative explanation suggested by Sansome and Philp (1932) is that " the production of some inhibitory substance normally induced by $\mathbf{S}_{\text {I }}$ may be stopped at the source by the presence of $\mathbf{S}_{3}$." The effect of dominance in Oenothera substantiates this second hypothesis.

Another expression of these effects was found in tetraploid Trifolium repens $(2 x=64)$ by Atwood (1944). Both self-compatible and self-incompatible plants were found in an $F_{1}$ family, and evidence was given that the self-compatible plants were those carrying 3 or 4 different alleles. He suggested that growth of pollen tubes carrying two different alleles may sometimes depend, not on a specific oppositional effect between the individual pollen tube and the style, but upon some new effect due to the presence of many different pollen genotypes in the style.

From all these data in different species, it is probable that tetraploidy has a number of general effects on incompatibility of which allele interaction in the pollen grain is the most powerful. The present study is of further experiments with tetraploid Oenothera organensis designed to define more clearly the nature and extent of these effects.

\section{TECHNIQUE}

(i) Chromosome doubling and identification of tetraploids

The method of chromosome doubling with colchicine and the identification of tetraploids by their 4-pored pollen grains have been 
described (Lewis, 1943a). This method of identification has continued to be efficient with one exception. A 3-year-old plant which had grown from a colchicined seedling and had produced tetraploid shoots in previous years, again produced shoots which appeared to be tetraploid and had 4-pored pollen. But on using these shoots as a female parent with another tetraploid plant, triploid offspring were produced, thus showing that the shoots were now periclinal chimæras composed of diploid inner and tetraploid outer tissue.

\section{(ii) Pollen-tube growth rate and staining}

The growth rates of pollen tubes were determined on cut flowers kept in a dark incubator at $30^{\circ} \mathrm{C}$. for 24 hours. As I have previously described, it is only under these conditions that the maximum information can be obtained from this kind of study ( $c f$. Lewis, I 942 ; Modlibowska, 1945).

In early experiments the styles were fixed in 90 per cent. alcohol, the inner tissue dissected out and stained in cotton blue (Emerson, I938). In later experiments the styles were fixed and stained simultaneously in an alcoholic solution of iodine in potassium iodide (iodine, I gm.; KI, I.5 gm. ; 30 per cent. alcohol, Ioo c.c.). The material can be examined within an hour of fixation or it can be kept indefinitely in the iodine solution for later examination. The whole style is merely squashed and not dissected ; this saves time and ensures that none of the tissue is lost. The pollen tubes show up very conspicuously as a result of their large starch grains, which are stained black.

\section{(iii) Testing the genotypes of tetraploids}

Any investigation of incompatibility in tetraploids pivots on the determination of the $\mathbf{S}$ genotypes of the plants. Without a sound knowledge of the genotypes we cannot be sure of our interpretation, since we must explain for each plant two unknown factors, genotype and incompatibility behaviour, from the results of behaviour alone. Since there are effects of tetraploidy that are unpredictable from the mechanism in diploids, results cannot be interpreted without hazard. With the genotypes irrefutably determined we have a firm basis for the interpretation of results.

A tetraploid plant that is a somatically doubled form of a known diploid, as in the case of the spontaneous tetraploid pear variety, Fertility, or the tetraploid shoots of a plant that has been treated with colchicine, presents no difficulty; it must be diallelic, ${ }^{*}$ e.g. Sy.y.x.x.

With sexual progeny of two tetraploids it is often necessary, however, to be able to discriminate between 8 different genotypes. In Oenothera organensis these genotypes can be tested accurately by applying the pollen of diploid plants of known $\mathbf{S}$ constitution and examining pollen-tube growth (described by Lewis, 1943a). Any S

* The extremely useful terms diallelic, triallelic and tetrallelic which refer to plants with 2, 3 and 4 different $\mathbf{S}$ alleles respectively were coined by Atwood (1944). 
allele present in a tetraploid style inhibits haploid pollen carrying the same allele but does not inhibit any other haploid pollen. These differences are as sharp when using a tetraploid style as when using a diploid. This method has been previously successful with several diallelic and one triallelic genotype and has now been extended to others including tetrallelic plants.

The reactions of all tetraploid genotypes, obtainable from 4 alleles, to pollen of diploid test plants are given in table I. In Oenothera it is possible to distinguish between a fully compatible $(++)$ and a half

TABLE I

Genotypes of tetraploid plants are determined by the incompatibility reactions with pollens of 6 different diploid plants. Reactions for all the possible genotypes obtainable with 4 alleles are given : - - , all pollen incompatible; ++, all pollen compatible ; +-, 50 per cent. compatible and 50 per cent. incompatible pollen.

\begin{tabular}{|c|c|c|c|c|c|c|}
\hline \multirow{2}{*}{ Tetraploid females } & \multicolumn{6}{|c|}{ Diploid male test plants } \\
\hline & $\mathbf{S}_{2.3}$ & $\mathbf{S}_{2.4}$ & $\mathbf{S}_{2.6}$ & $\mathbf{S}_{3.4}$ & $\mathbf{S}_{3.6}$ & $\mathbf{S}_{4.6}$ \\
\hline $\mathrm{S}_{2.2 \cdot 3 \cdot 3}$ & $-\ldots$ & +- & +- & +- & +- & ++ \\
\hline $\mathbf{S}_{2.2 .4 .4}$ & +- & -- & +- & +- & $+t$ & +- \\
\hline $\mathbf{S}_{2.2 .6 .6}$ & +- & +- & $\bar{t}-$ & $+t$ & +- & +- \\
\hline $\mathbf{s}_{3 \cdot 3 \cdot 4 \cdot 4}$ & + & + & $+t$ & $\overline{t-}$ & \pm & + \\
\hline $\mathbf{S}_{4.4 .6 .6}$ & $+t$ & +- & +- & +- & +- & -- \\
\hline $\mathbf{S}_{2 \cdot 3 \cdot 4}\left(\begin{array}{l}2 \\
3\end{array}\right.$ & -- & -- & +- & -- & +- & +- \\
\hline $\mathbf{S}_{2.3 .6}\left(\begin{array}{l}2 \\
3\end{array}\right)$ & -- & +- & $-\cdots$ & +- & -- & +- \\
\hline $\mathbf{S}_{2.4 .6}\left(\begin{array}{l}2 \\
4\end{array}\right)$ & +- & -- & -- & +- & +- & -- \\
\hline $\mathbf{S}_{3 \cdot 4 \cdot 6}\left(\begin{array}{l}3 \\
4 \\
6\end{array}\right)$ & +- & +- & +- & -- & -- & -- \\
\hline$S_{2.3 \cdot 4.6}$ & -- & -- & -- & -- & - & -- \\
\hline
\end{tabular}

compatible $(+-)$ pollination, but in less favourable species even if this cannot be done, so long as incompatible combinations can be differentiated from the two compatible, $(++)$ and $(+-)$, there are still decisive differences between the genotypes as table I shows.

It is, however, impossible to determine by this method alone which of the alleles in a triallelic plant is duplicated ; for this reason

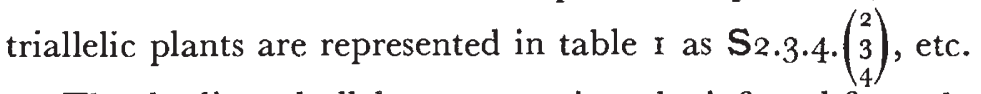

The duplicated allele can sometimes be inferred from the genotype of the parental plants. For example, among the $F_{1}$ progeny of two diallelic plants differing in both alleles there will be 4 different triallelic genotypes. The duplicated allele in each is known because it is fixed by the genotypes of the parents. For example, in the cross 
$\mathbf{S}_{4.4 .6 .6 \times} \mathbf{S}_{2.2 .3 .3}$. any progeny in which $\mathbf{S}_{2}, \mathbf{S}_{3}$ and $\mathbf{S}_{4}$ have been detected must have the $\mathbf{S}_{4}$ allele in duplicate.

But in a cross such as $\mathbf{S}_{4 \cdot 4.6 .6} \times \mathbf{S}_{3.4 .6 .6}$ the duplicated allele may be one of two, so that the triallelic plants may be either $\mathbf{S}_{3} .6 .4 .4$ or

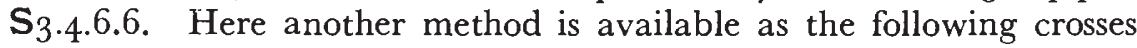
show :-

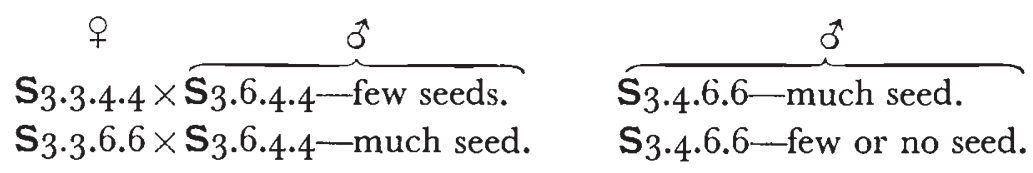

Thus, the plants to be tested, when used as males onto suitable plants as females, behave differently according to which of the alleles is duplicated.

The results of analysing the genotypes of two families raised from reciprocal crosses between $\mathbf{S}_{4.4 .6 .6}$ and $\mathbf{S}_{2.2 .3 .3}$ plants are given with the numbers to be expected on random chromosome segregation in table 2. It is evident that there is a significant deviation from

TABLE 2

The number of genotypes found by analysing the progeny of two $F_{1}$ families, $\mathbf{S}_{4} \cdot 4.6 .6 \times \mathbf{S}_{2.2 .3 .3}$ and the reciprocal, by pollinating each plant with 6 different diploid test plants

\begin{tabular}{|c|c|c|c|c|}
\hline \multirow{2}{*}{$\begin{array}{c}\text { Genotypes of } \\
\text { progeny } \\
\text { S... }\end{array}$} & \multicolumn{3}{|c|}{ Observed numbers of plants } & \multirow{2}{*}{$\begin{array}{l}\text { Number expected on } \\
\text { random chromosome } \\
\text { segregation }\end{array}$} \\
\hline & $\begin{array}{l}\mathrm{S}_{4 \cdot 4 \cdot 6.6} \\
\times \\
\mathrm{S}_{2 \cdot 2 \cdot 3 \cdot 3}\end{array}$ & Reciprocal & $\begin{array}{l}\text { Total } \\
\text { progeny } \\
(30)\end{array}$ & \\
\hline $\begin{array}{l}2.2 .4 \cdot 4 \\
2.2 .6 .6 \\
3 \cdot 3 \cdot 4 \cdot 4 \\
3 \cdot 3 \cdot 6.6 \\
2.2 .4 .6 \\
2 \cdot 3 \cdot 4 \cdot 4 \\
2 \cdot 3 \cdot 6.6 \\
3 \cdot 3 \cdot 4 \cdot 6 \\
2 \cdot 3 \cdot 4.6\end{array}$ & $\begin{array}{l}0 \\
0 \\
2 \\
2 \\
2 \\
2 \\
0 \\
5 \\
3\end{array}$ & $\begin{array}{l}0 \\
0 \\
2 \\
0 \\
1 \\
2 \\
3 \\
5 \\
1\end{array}$ & $\begin{array}{r}0 \\
0 \\
4 \\
2 \\
3 \\
4 \\
3 \\
10 \\
4\end{array}$ & $\begin{array}{r}0.83 \\
0.83 \\
0.83 \\
0.83 \\
3.33 \\
3.33 \\
3.33 \\
3.33 \\
13.34\end{array}$ \\
\hline
\end{tabular}

the expected values, and in order to find the cause the number of functioning gametes are analysed separately from both parents (table 3). From this analysis we can see that the deviation is due to the $\mathbf{S}_{2.2 .3 .3}$ plant only, which is producing a large deficiency of $\mathbf{S}_{2.2}$ and $\mathbf{S}_{2.3}$ pollen grains and eggs.

Emerson's (1938) data show that segregation in $\mathbf{S}_{2.3}$ diploid plants is not disturbed in a similar way. The genetic output of $\mathbf{S}_{2.3}$ diploid plants is 33 of $\mathbf{S}_{2}$ and 36 of $\mathbf{S}_{3}$, which obviously does not differ significantly from random segregation. Naturally my $\mathbf{S}_{2.2 .3 .3}$ plant differs in many genes from the $\mathbf{S}_{2.3}$ plants which Emerson used, and it may be that some of these genes cause the abnormal segregation. Alternatively, the disturbance may be due to the new condition of 
tetraploidy, which seems to reduce fertility in $\mathbf{S}_{2.2}$ and $\mathbf{S}_{2.3}$ gametes more than in $\mathbf{S}_{3.3}$ gametes.

TABLE 3

Further analysis of the data in table 2, giving the output of functional gametes from the two parental plants separately. This shows that the deviation from expectation comes from one plant only.

\begin{tabular}{|c|c|c|c|c|c|}
\hline $\begin{array}{c}\text { Parental } \\
\text { genotype }\end{array}$ & Gametes & $\begin{array}{c}\text { Observed } \\
\text { numbers }\end{array}$ & Expected & $\chi^{2}$ & $p$ \\
\cline { 1 - 4 } $\mathbf{S}_{2.2 .3 .3}$ & $\mathbf{S}_{2.2}$ & 3 & 5 & $29 \cdot 0$ & \multirow{2}{*}{ Very small } \\
& $\mathbf{S}_{2.3}$ & $\mathbf{S}_{3.3}$ & 16 & 5 & \\
& $\mathbf{S}_{4.4}$ & 8 & 5 & & \\
$\mathbf{S}_{4.4 .6 .6}$ & $\mathbf{S}_{4.6}$ & 17 & 20 & $2 \cdot 2$ & $0.50-0.30$ \\
& $\mathbf{S}_{6.6}$ & 5 & 5 & & \\
\hline
\end{tabular}

Two other small families were raised in order to obtain certain genotypes that were wanted for further experiments. One of these was an $F_{1}$ from a cross :-

$\mathbf{S}_{3.4 .6 .6} \times \mathbf{S}_{2.2 .3 .3}$, which produced :

$4: \mathbf{S}_{2.2 .3 .6}$ and $2: \mathbf{S}_{2.2 .3 .4}$ plants; a result which does not differ significantly from expectation.

The other family was raised from a cross :-

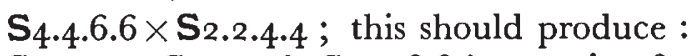

$\mathbf{S}_{2.2 .4 .4}, \mathbf{S}_{2.2 .4 .6}, \mathbf{S}_{2.2 .6 .6}$ in a ratio of $\mathrm{I}: 4: \mathrm{I}$.

The progeny consisted of $6: 6: 0$ and three unexpected plants. Two of these plants repelled the pollen of all 6 diploid test plants. The tests were repeated 4 times and it was concluded that these plants were $\mathbf{S}_{2.3 .4 .6}$ (see table I) ; the third plant reacted to the pollen

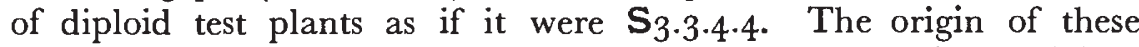
three plants is at present unexplained. The genotypes of the original parents have been retested and found to be correct. Furthermore, one of these anomalous tetrallelic plants was tested with certain tetraploid plants and it was found to behave differently to tetrallelic plants from families in which they were expected. Whether there is some effect which has hitherto not been found in tetraploid Oenothera cannot be decided until the original cross has been repeated. Further work is in progress to clear up this anomalous behaviour.

\section{ALLELIC COMPETITION WITH SELF-POLLINATION \\ (i) Effect of modifiers}

Since the plants used in these experiments are not genetically identical or isogenic there will be modifying genes segregating. In the diploid Oenothera stocks, from which the tetraploid plants were derived, the modifiers that were segregating had a very slight effect on incompatibility; the only one which could be detected gave a slightly stronger incompatibility at lower temperatures (Lewis, 1942). 
In the tetraploid, however, there are new possibilities of modifiers interacting in the pollen grains, and of dosage differences in the somatic tissue of the style. A priori these effects should be smaller than any effects in the diploid ; but it is possible that the incompatibility, being much weaker in the tetraploid, is more sensitive to the effect of modifiers.

Again it is possible that recombination of blocks of modifiers that never or rarely occur in diploids may occur in the tetraploid, due to a shift of chiasmata by the changed condition of pairing in a quadrivalent. Chiasmata, however, seem to be more and not less restricted in a quadrivalent than in a bivalent.

In these experiments, wherever possible, observations have been made on a number of different plants for each genotype, and thus any effect of modifiers will be accounted for in the analysis of variance.

\section{(ii) Pollen-tube growth}

All plants were self-pollinated and examined for pollen-tube growth and seed production. The results of pollen-tube measurements

\section{TABLE 4}

Results of pollen-tube measurements in self-pollinated styles of tetraploids. The means of maximum lengths in individual plants are given with comparable figures from diploid plants selfed and compatibly crossed

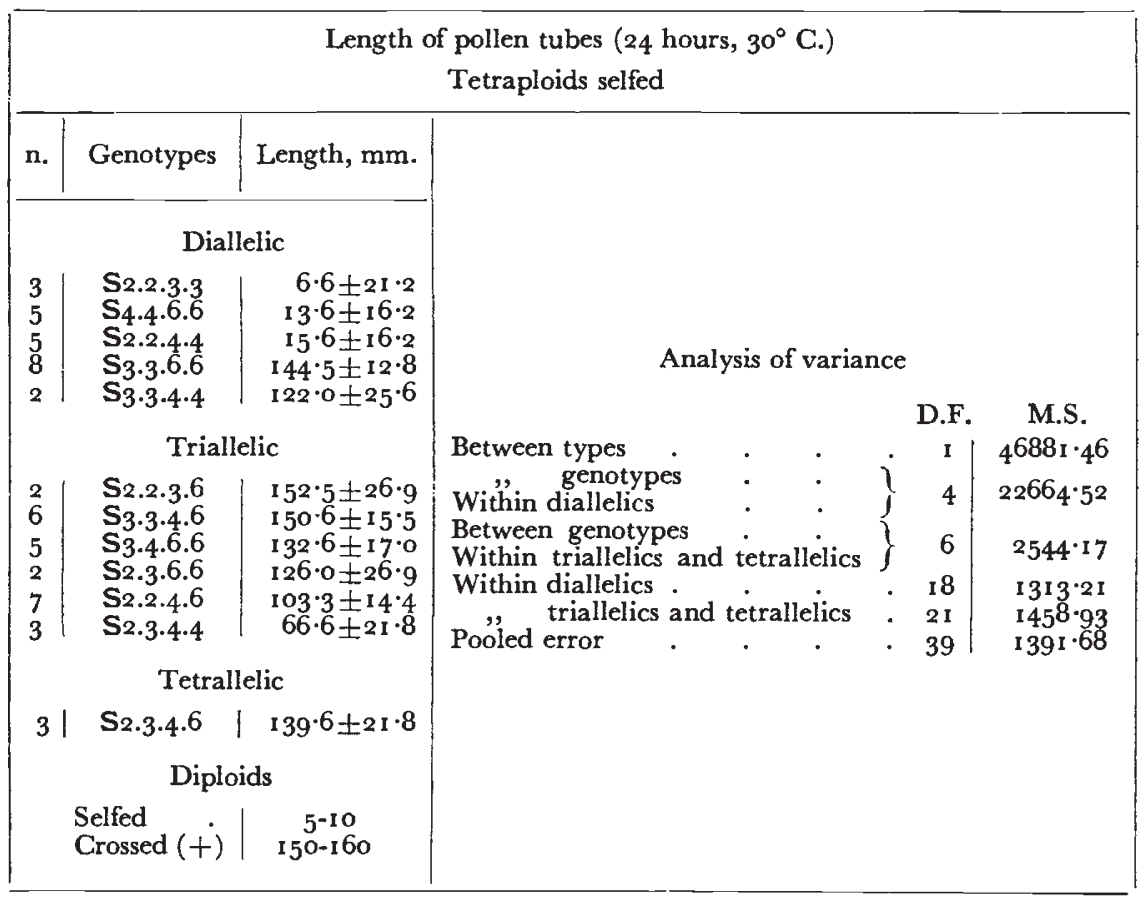

are given in table 4 . The analysis of variance shows a significant difference between the diallelic type and the tri- and tetrallelic types, 
and a significant difference between genotypes within the diallelic type.

The difference between the diallelic and the other types is due solely to a difference between genotypes within the diallelics. In fact these fall into two classes: (I) Genotypes with short pollen tubes that are comparable with the incompatible pollen tubes in diploids, and (2) genotypes with long pollen tubes comparable with the compatible tubes in diploids. The triallelic and tetrallelic types all have long tubes and do not differ significantly from the second class of diallelic genotypes, i.e. those with long tubes.

This difference within the diallelic type has already been reported for some of these genotypes (Lewis, 1943a), and the present data not only confirms but extends it to other genotypes.

The first question arising from the data is: Which pollen genotypes produce the long tubes that are found in some diallelic genotypes and in the tri- and tetrallelic types? From the short tubes found in the first three diallelic genotypes in table 4 we know that all homogenic pollen grains $\mathbf{S}_{2.2}, \mathbf{S}_{3.3}, \mathbf{S}_{4.4}$ and $\mathbf{S} 6.6$, and the heterogenic pollen grains $\mathbf{S}_{2.3}, \mathbf{S}_{2.4}$ and $\mathbf{S}_{4.6}$, all give short tubes when growing in styles carrying these alleles. From this we can deduce that the long tubes in the two diallelic genotypes $\mathbf{S} 3.3 .6 .6$ and $\mathbf{S}_{3.3 .4 .4}$ are derived from the heterogenic pollen grains $\mathbf{S}_{3.6}$, $\mathrm{S}_{3.4}$.

A further question that arises is, why do all the triallelic types produce long tubes while some diallelics produce short tubes? The answer is simply that all the triallelics, with the exception of $\mathbf{S}_{2.2 .4 .6}$ produce one or both of the pollen types $\mathbf{S}_{3} .6$ and $\mathbf{S}_{3.4}$ which, as we have seen, produce long tubes. About the other triallelic plant we know that $\mathbf{S}_{2.2}, \mathbf{S}_{2.4}$ and $\mathbf{S}_{4.6}$ pollen grains produce short tubes.

We can also infer that the remaining type $\mathbf{S}_{2} .6$ pollen would produce the long tubes from the comparison of the growth rates of pollen tubes in self- and cross-pollinations of other diallelic and triallelic plants as follows (means of four plants) :-

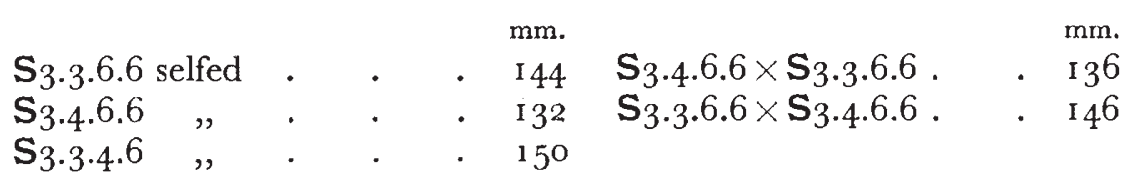

None of the differences are significant. Now in all these pollinations one or both of the pollen grains $\mathbf{S}_{3} .6$ or $\mathbf{S}_{3.4}$ are involved. These pollen grains therefore do not grow differently whether they are derived from a triallelic or a diallelic parent, or whether they are growing in a triallelic or diallelic style.

Since we know that an $\mathbf{S}_{2.2 .4 .6}$ plant produces long tubes after self-pollination and that $\mathbf{S}_{2.2}, \mathbf{S}_{2.4}$ and $\mathbf{S}_{4.6}$ pollen grains produce short tubes in styles carrying these alleles, we can safely infer that 
it is the $\mathbf{S}_{2.6}$ pollen grains which are producing the long tubes in this case ; and they do so whether they are derived from a triallelic or diallelic plant.

It is clear then that in Oenothera the triallelic and tetrallelic plants give long pollen tubes after self-pollination solely because they produce certain heterogenic pollen grains. They do not do so because of any property special to triallelics and tetrallelics such as their output of more than one type of heterogenic pollen as suggested for Trifolium repens by Atwood (1944). The results of self pollen-tube measurements in tetraploid Oenothera are summarised in table 5 .

\section{TABLE 5}

Different types of pollen-tube growth according to the gene constitution of diploid pollen. Short-tube genotypes, italics; long-tube genotypes, bold face. Note.-The long-tube types are the heterogenic pollen grains showing competition between the two $\mathbf{S}$ alleles (i.e. $2 \cdot 6,3 \cdot 4$ and $3 \cdot 6$ but not $2 \cdot 3$ or $2 \cdot 4$ or $4 \cdot 6$ ).

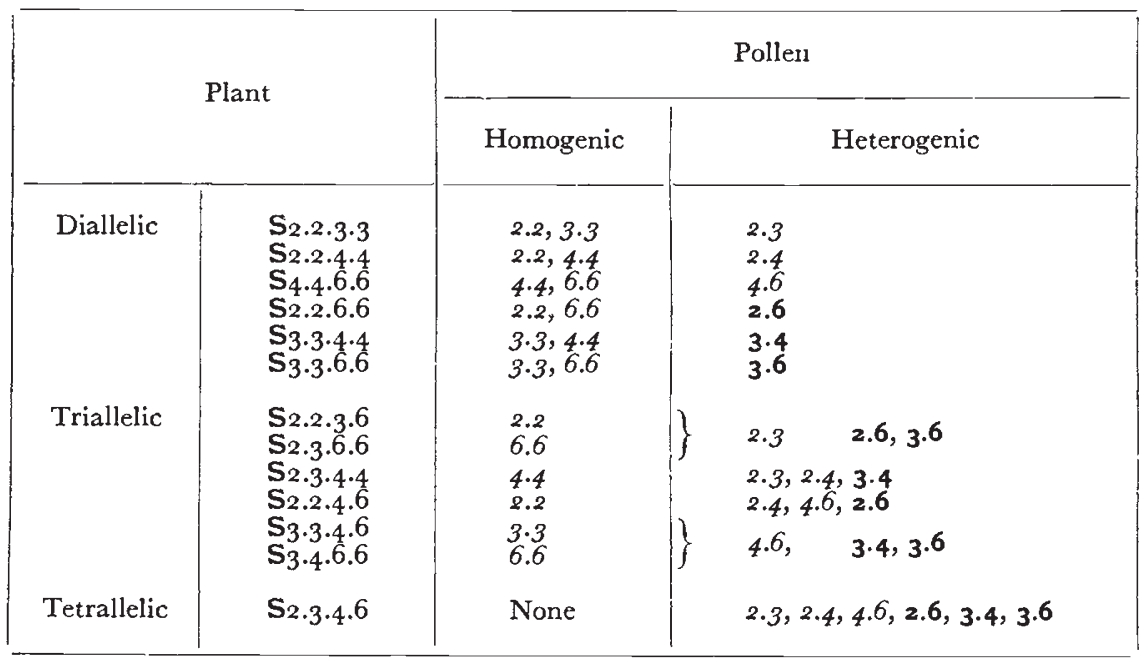

Now with this evidence from Oenothera, and the evidence from Pyrus communis and Petunia, detailed in the introduction, it is probable that some combinations of pairs of $\mathbf{S}$ alleles compete when together in the same pollen grain so that neither allele can produce its normal effect, and that other pairs do not compete in this way.

\section{(iii) Seed set}

Diploid plants of Oenothera organensis produce no seeds after selfpollination (Emerson, 1938). Seed production in the tetraploids is given in table 6, from which it is evident that no seeds are produced by diallelic plants but that tetrallelic plants set about one seed per flower pollinated. If these results are compared with the mean of 64 . I seeds per flower crossed with compatible pollen, it is clear that none of these tetraploid genotypes are really self-compatible. 
We have seen that in all the triallelic, the tetrallelic and in two of the diallelic plants the self pollen tubes grow to the base of the style nearly at the same rate as compatible tubes do. It is in the ovary, however, that these two kinds of pollen tubes show a difference. No tubes were found in the ovary at 48 hours after self-pollination, but many were found there after compatible pollination. Thus, although there is a great weakening of incompatibility by allele competition in the heterogenic pollen grain in Oenothera which allows

TABLE 6

Seed production after self-pollination in tetraploid plants with different $\mathbf{S}$ genotypes

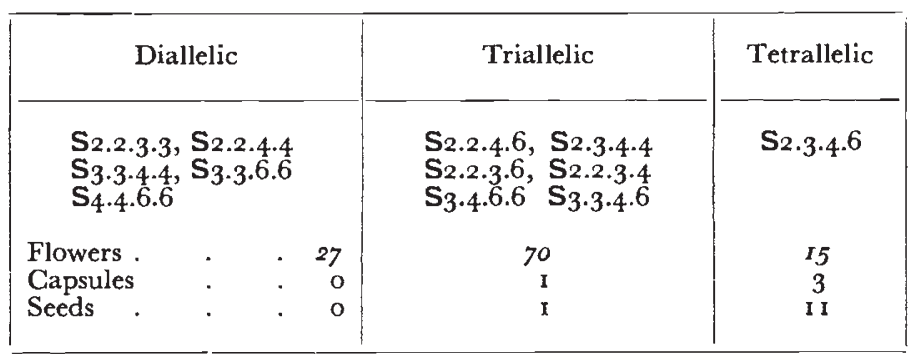

the pollen tubes to grow $160 \mathrm{~mm}$. instead of only $5 \mathrm{~mm}$. as in the diploid, this is not enough to overcome the strong incompatibility barrier in this species.

Superficially, these results contrast with those found in Petunia, Pyrus, Solanum and Trifolium in which seed is produced freely after selfing, but fundamentally the difference is only slight. The normal incompatibility reaction is much stronger in Oenothera than in these other species, consequently the effects due to polyploidy are not sufficient to overcome it entirely.

It is this partial breakdown of incompatibility in Oenothera that makes a more complete analysis of the effects of gene interaction possible. If seeds were produced by heterogenic pollen grains after selfing as in the other species, it would be impossible to discriminate between the effects that are described in the next section.

\section{ALLELIC BALANCE BETWEEN STYLE AND POLLEN IN INTERCROSSES}

The cross-pollinations are divided into three groups according to how the genotypes of the mated plants are related. In the two groups to be considered first the crosses are balanced, as opposed to the third group in which they are unbalanced. They are balanced because the relationship of the alleles in the pollen and the style are similar to, either the incompatible or the compatible, matings in diploids. In the first group all the $\mathbf{S}$ alleles in the male are present also in the 
female; this, therefore, corresponds to the incompatible matings in diploids. In the second group there are at least two alleles (like or unlike) in the male that are not present in the female; this corresponds to the compatible cross in diploids.

In group I, as expected from the results of self-pollination, few seeds are produced (table 7). Furthermore, no seeds are produced by the tetrallelic plants intercrossed, while this genotype when selfed gave eleven seeds from fifteen flowers. But this difference is not significant; because the eleven seeds came only from two plants and these two plants were used in only one of the seven crosses. Nevertheless the difference is of interest, because in tetraploid Trifolium repens triallelic and tetrallelic plants also set more seeds on selfing than on intercrossing, and in this species the difference was significant (Atwood, I944).

In group 2, in contrast to group I, each male plant produces at least one type of pollen containing two alleles, none of which are present in the female parent of the cross. In these crosses the seed set is high in accordance with expectation (table 7).

But there are significant differences between the seed sets of different classes within group 2. The diallelic $\times$ triallelic and the diallelic $\times$ tetrallelic combinations are significantly less productive than the others. The explanation for this is to be found within the diallelic $\times$ triallelic matings. In the first two crosses, $\mathbf{S}_{2.2 .3 .3} \times \mathbf{S}_{3.3 .4 .6}$ and $\mathbf{S}_{2.2 .3 .3} \times \mathbf{S}_{2.2 .4 .6}$, the functioning pollen grains are heterogenic, $\mathbf{S}_{4} .6$, and the seed set is five per flower, while in the other two crosses the pollen grains are homogenic and the seed set is 53.6 per flower.

The following comparison is based on table 6 :-

$$
\begin{array}{llll}
\text { Functioning pollen . } & \text {. Heterogenic } & \text { Homogenic } \\
\text { Seeds per flower } & \text {. } 16 \cdot 5 \pm 5 \cdot 7 & 64 \cdot \mathrm{I} \pm 6 \cdot \mathrm{I}
\end{array}
$$

It is evident that the low seed set in some of the balanced compatible crosses is mainly due to the pollen grains being heterogenic for $\mathbf{S}$ alleles, and that these heterogenic grains are about one-third as effective as the homogenic grains in achieving fertilisation.

There is further evidence on this point in section $3(c f$. tables 2 and 3), where a significant deficiency of functioning heterogenic gametes from an $\mathbf{S} 2.2 .3 .3$ plant was found. With a second plant, $\mathbf{S}_{4.4 .6 .6}$, the deficiency was not significant but the number of heterogenic gametes was below expectation, particularly on the male side. This lowering of viability or fertility of heterogenic gametes is discussed later when further data have been considered and analysed.

The third group to be considered consists of crosses which are unbalanced. They are unbalanced because the only pollen genotypes that are likely to function, if in fact they do function, have one $\mathbf{S}$ allele that is present and one that is not present in the female plant. 
For example, in the cross $\mathbf{S}_{2.2 .3 .4} \times \mathbf{S}_{2.2 .4 .6}$, if there are any functional pollen grains they will be either $\mathbf{S}_{4.6}$ or $\mathbf{S}_{2.6}$, both of which have

TABLE 7

Seed production of intercrosses between pairs of genotypes that are balanced; balanced-crosses are those in which all the pollen genotypes have both $\mathbf{S}$ alleles present in the female; balanced + crosses are those in which at least one type of pollen has both $\mathbf{S}$ alleles not present in the style.

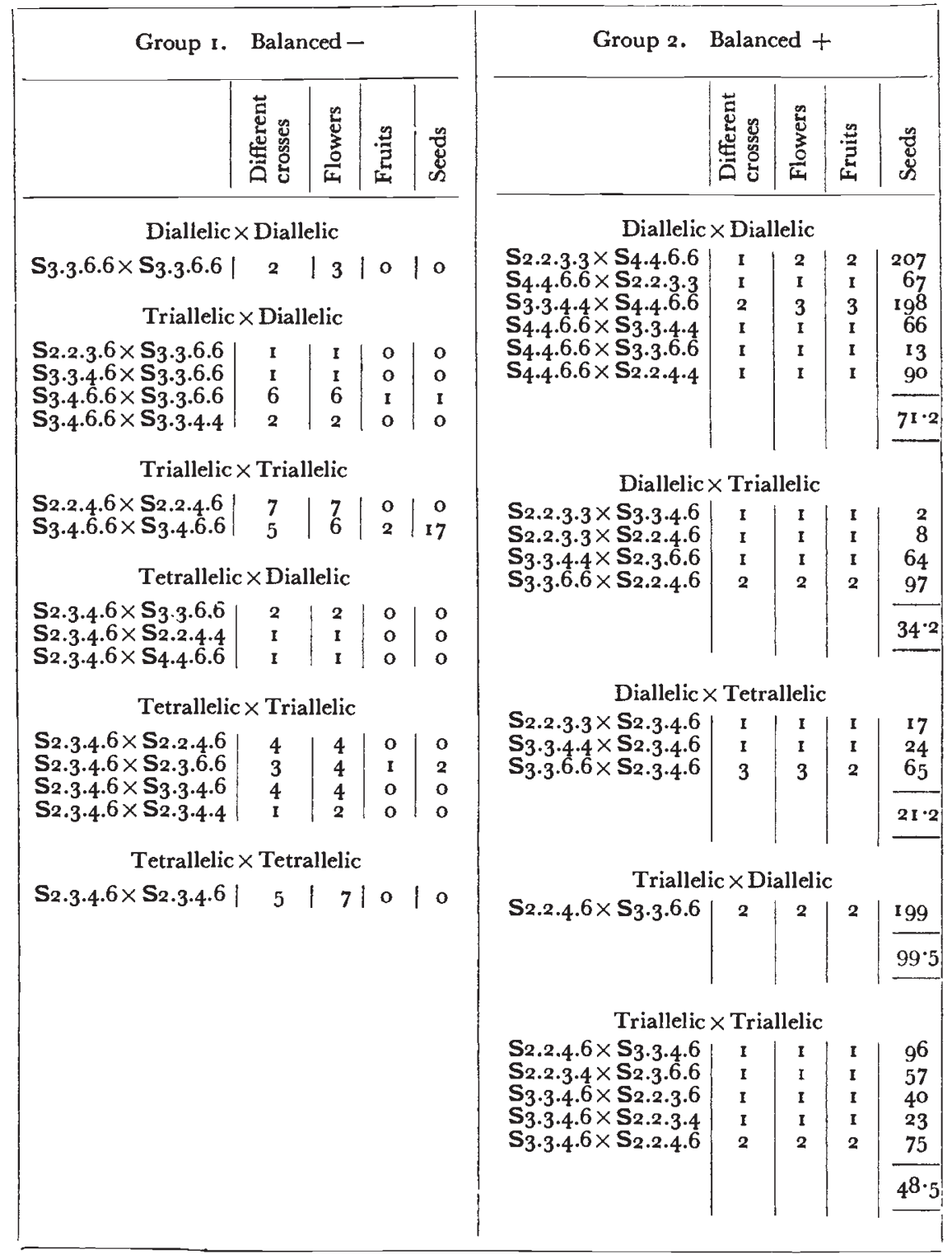

only one allele common to the female parent. Furthermore, the allele common to the pollen grain and female parent may be either 
in single dose in the female as in the case of $\mathbf{S}_{4}$, or in double dose as in the case of $\mathbf{S}_{2}$.

To denote these differences, pollen grains are represented as Sx.y when the Sx allele is present in either single or double dose and the Sy not present in the female. It is evident that by making certain crosses it is possible to compare $\mathbf{S x} . y$ with $\mathbf{S} x . \mathbf{y}$. In other words, it is possible to determine whether there is any dominance between alleles in the pollen grains.

As the data show (table 8) some of these unbalanced crosses are completely compatible, setting 9-29 seeds per flower pollinated;

\section{TABLE 8}

Seed production of intercrosses between pairs of genotypes that are unbalanced; i.e. the only pollen grains which have an $\mathbf{S}$ allele not present in the female parent have one allele present and one allele not present in the female. A suffix in bold-face type, e.g. Sx, signifies that this allele is present in the female in single or double dose; a suffix in ordinary type, e.g. S $x$ denotes that this allele is absent from the female.

\begin{tabular}{|c|c|c|c|c|c|c|}
\hline & & & & Seeds & Unbalanced pc & ollen genotypes \\
\hline & & & & flower & Incompatible & Compatible \\
\hline 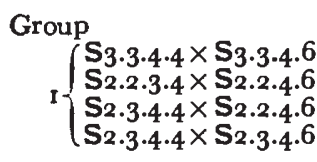 & $\begin{array}{l}I \\
6 \\
2 \\
2\end{array}$ & $\begin{array}{l}1 \\
8 \\
3 \\
2\end{array}$ & $\begin{array}{l}1 \\
5 \\
3 \\
2\end{array}$ & $\begin{array}{r}6 \cdot 0 \\
20 \cdot 7 \\
15 \cdot 0 \\
29 \cdot 0\end{array}$ & $\begin{array}{l}\cdots \\
\cdots \\
\cdots\end{array}$ & $\begin{array}{l}\mathbf{S}_{3.6}, \mathbf{S}_{4.6} \\
\mathbf{S}_{2.6}, \mathbf{S}_{4.6} \\
\mathbf{S}_{2.6}, \mathbf{S}_{4.6} \\
\mathbf{S}_{2.6}, \mathbf{S}_{3.6}, \mathbf{S}_{4.6}\end{array}$ \\
\hline 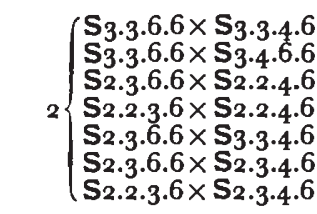 & $\begin{array}{l}5 \\
6 \\
5 \\
5 \\
2 \\
1 \\
4\end{array}$ & $\begin{array}{l}5 \\
6 \\
6 \\
5 \\
2 \\
1 \\
4\end{array}$ & $\begin{array}{l}\mathbf{1} \\
\mathbf{1} \\
\mathbf{0} \\
\mathbf{0} \\
0 \\
0 \\
0 \\
0\end{array}$ & $\begin{array}{l}2 \cdot 4 \\
0 \cdot 5 \\
0 \cdot 0 \\
0 \cdot 0 \\
0 \cdot 0 \\
0 \cdot 0 \\
0 \cdot 0\end{array}$ & \begin{tabular}{|l|}
$\mathbf{S}_{3.4}, \mathbf{S}_{4.6}$ \\
$\mathbf{S}_{3.4}, \mathbf{S}_{4.6}$ \\
$\mathbf{S}_{2.4}, \mathbf{S}_{4.6}$ \\
$\mathbf{S}_{2.4}, \mathbf{S}_{4.6}$ \\
$\mathbf{S}_{3.4}, \mathbf{S}_{4.6}$ \\
$\mathbf{S}_{2.4}, \mathbf{S}_{3.4}, \mathbf{S}_{4.6}$ \\
$\mathbf{S}_{2.4}, \mathbf{S}_{3.4}, \mathbf{S}_{4.6}$
\end{tabular} & \\
\hline $3\left\{\begin{array}{l}\mathbf{S}_{3.3 .6 .6 \times} \mathbf{S}_{2.3} .6 .6 \\
\mathbf{S}_{3.3 .4 .4} \times \mathbf{S}_{2 \cdot 3 \cdot 4 \cdot 4} \cdot 4 \times \mathbf{S}_{2.3 \cdot 4 \cdot 6}\end{array}\right.$ & $\begin{array}{l}7 \\
1 \\
4\end{array}$ & $\begin{array}{l}7 \\
2 \\
4\end{array}$ & $\begin{array}{l}3 \\
2 \\
4\end{array}$ & $\begin{array}{r}8 \cdot 6 \\
19 \cdot 0 \\
22 \cdot 0\end{array}$ & $\begin{array}{l}\cdots \\
\cdots \\
\cdots\end{array}$ & $\begin{array}{l}\mathbf{S}_{2.3}, \mathbf{S}_{2.6} \\
\mathbf{S}_{2.3}, \mathbf{S}_{2.4} \\
\mathbf{S}_{2.3}, \mathbf{S}_{2.4}, \mathbf{S}_{2.6}\end{array}$ \\
\hline $4\left\{\begin{array}{l}\mathbf{S}_{2.2 .3 .3} \times \mathbf{S}_{2.2 .3 .4} \\
\mathbf{S}_{2.2 .4} \times \mathbf{S}_{2.2 .34} \\
\mathbf{S}_{2.3 .6 .6} \times \mathbf{S}_{2.2 .3 .4} \\
\mathbf{S}_{2.2 .3 .6} \times \mathbf{S}_{2.2 .3 .4} \\
\mathbf{S}_{2.2 .4 .6} \times \mathbf{S}_{2.2 .3 .6} \\
\mathbf{S}_{2.2 .3 .4} \times \mathbf{S}_{2.2 .3 .6}\end{array}\right.$ & $\begin{array}{l}4 \\
1 \\
5 \\
5 \\
4 \\
1\end{array}$ & $\begin{array}{l}7 \\
1 \\
5 \\
6 \\
4 \\
1\end{array}$ & $\begin{array}{l}0 \\
0 \\
1 \\
0 \\
0 \\
0\end{array}$ & $\begin{array}{l}0 \cdot 0 \\
0 \cdot 0 \\
0 \cdot 4 \\
0 \cdot 0 \\
0 \cdot 0 \\
0 \cdot 0\end{array}$ & $\begin{array}{l}S_{2.4}, S_{3 \cdot 4} \\
S_{2.3}, S_{3 \cdot 4} \\
S_{2.4}, S_{3 \cdot 4} \\
S_{2.4}, S_{3 \cdot 4} \\
S_{2.3}, S_{3.6} \\
S_{2.6}, S_{3.6}\end{array}$ & \\
\hline $5\left\{\begin{array}{l}\mathbf{S}_{4.4 .6 .6 \times} \mathbf{S}_{3.4 .6 .6} \\
\mathbf{S}_{2.2 .4 .6 \times} \times \mathbf{S}_{2.3 .4 .6}\end{array}\right.$ & $\begin{array}{l}3 \\
5\end{array}$ & $\begin{array}{l}4 \\
5\end{array}$ & $\begin{array}{l}3 \\
5\end{array}$ & $\begin{array}{l}14.0 \\
16 \cdot 6\end{array}$ & $\begin{array}{l}\cdots \\
\cdots\end{array}$ & $\begin{array}{l}\mathbf{S}_{3.4}, \mathbf{S}_{3.6} \\
\mathbf{S}_{2.3}, \mathbf{S}_{3.4}, \mathbf{S}_{3.6}\end{array}$ \\
\hline
\end{tabular}

others are completely incompatible, setting no seeds; and yet two others are partially compatible, setting $0 \cdot 5-2 \cdot 4$ seeds per flower. The latter is provisionally classed as incompatible, since balanced incompatible crosses occasionally produce a few seeds (table 7 ).

The explanation of these differences must be found in the only 
two variables between the crosses, viz. (I) The dosage in the style of the allele which is common to the pollen and style differs between crosses, and (2) the actual alleles which are common to pollen and style differ between crosses.

Let us consider the style dosage difference first. Among the unbalanced crosses (table 8 ) evidence of a negative kind can be obtained from the incompatibility of a pollen genotype in styles carrying one of its alleles in single or double dose. For example, $\mathrm{S}_{4} .6$ pollen grain is incompatible in all crosses in which there are either one or two S6 alleles in the style. The $\mathbf{S}_{2.4}$ pollen genotype behaves similarly. In these cases dosage appears to have no effect.

Further evidence, based on a more delicate test, comes from the pollen-tube growth of haploid pollen. This test is particularly sensitive to any change of genotype or environment (Lewis, I942), and no effect on the growth of haploid pollen tubes of different dosages in the style has been found with any of the alleles. It is highly probable, therefore, that different dosages in the style have no effect, and in this work it is assumed to be so.

The differences in seed set found among unbalanced crosses must, therefore, be due to the only other variable-the different $\mathbf{S}$ alleles involved. The most striking example is seen by comparing, in table 8, the crosses in group I with those in group 2. Group I crosses have a normal seed set, showing that they are compatible. In these crosses there are two or three different pollen genotypes, each of which has one allele present and one not present in the female parent. Thus it might be expected that any one or all of the pollen types function. A discrimination can be made by eliminating those pollen genotypes which are present in incompatible crosses. Since S3.6 and $\mathbf{S} 2.6$ appear in incompatible crosses in group 4 the only compatible pollen in group I is $\mathbf{S} 4.6$. The female plants in this group all have $\mathbf{S}_{4}$ but lack $\mathbf{S} 6$. In contrast, group 2 crosses show that $\mathbf{S}_{4} .6$ pollen is incompatible on a female with the reverse condition, i.e. with $\mathbf{S 6}$ but lacking $\mathbf{S}_{4}$.

A similar comparison of group 5 with group 2 shows that $\mathbf{S}_{3.4}$ pollen is compatible in a style carrying $\mathbf{S}_{4}$ but lacking $\mathbf{S}_{3}$, and is incompatible in a style with $\mathbf{S}_{3}$ but lacking $\mathbf{S}_{4}$.

It is not possible from the data in table 8 alone to distinguish which of the three pollen genotypes in group 3 is compatible, but an analysis of the next generation seedlings (family 6/46, table 9 ) gives decisive discrimination. From this it is clear that only $\mathbf{S}_{2.3}$ pollen is compatible and this is in a style carrying $\mathbf{S}_{3}$ but not $\mathbf{S}_{2}$; in a style with the reversed condition, i.e. with $\mathbf{S}_{2}$ but lacking $\mathbf{S}_{3}$, this pollen genotype is incompatible.

The other family analysed in table 9 gives conclusive confirmation to the deduction made above that it is the $\mathbf{S}_{4} .6$ pollen that is compatible in group I crosses. 
TABLE 9

Genotypes of progenies from two crosses listed in Table 8 analysed to show which of the pollen genotypes are compatible

\begin{tabular}{|c|c|c|c|c|}
\hline \multicolumn{5}{|c|}{ Family $6 / 46 . \quad S_{3.3 \cdot 4.6 \times S_{2.3 .4 .6}}$} \\
\hline & Found & \multicolumn{3}{|c|}{$\begin{array}{l}\text { Expected numbers with the following } \\
\text { compatible pollen }\end{array}$} \\
\hline & & $\mathbf{S}_{2.3}$ & $\mathbf{S}_{2.4}$ & $\mathbf{S}_{2.6}$ \\
\hline $\mathrm{S}_{2 \cdot 3 \cdot 4 \cdot 6}$ & 1 & $I \cdot 3$ & $2 \cdot 6$ & $2 \cdot 6$ \\
\hline $\mathrm{S}_{2 \cdot 3 \cdot 6}\left(\begin{array}{l}3 \\
6\end{array}\right)$ & 4 & $2 \cdot 6$ & $0 \cdot 0$ & $3 \cdot 9$ \\
\hline $\mathbf{S}_{2 \cdot 3 \cdot 3 \cdot 3}$ & 3 & $x \cdot 3$ & $0 \cdot 0$ & $0 \cdot 0$ \\
\hline $\mathbf{S}_{2 \cdot 3 \cdot 4}\left(\begin{array}{l}3 \\
4\end{array}\right)$ & o & $2 \cdot 6$ & $3 \cdot 9$ & $0 \cdot 0$ \\
\hline $\mathrm{S}_{2 \cdot 4 \cdot 6}\left(\begin{array}{l}4 \\
6\end{array}\right)$ & o & $0 \cdot 0$ & $I \cdot 3$ & $1 \cdot 3$ \\
\hline \multicolumn{5}{|c|}{ Family $18 / 46 . \quad S_{2.2 .3 .4} \times S_{2.2 .4 .6}$} \\
\hline & Found & \multicolumn{3}{|c|}{$\begin{array}{l}\text { Expected numbers with the following } \\
\text { compatible pollen }\end{array}$} \\
\hline & & \multicolumn{2}{|c|}{$\mathrm{S}_{4.6}$} & $\mathrm{~S}_{2.6}$ \\
\hline $\mathrm{S}_{2 \cdot 4} \cdot 6\left(\begin{array}{l}2 \\
4\end{array}\right)$ & 3 & \multicolumn{2}{|c|}{$6 \cdot 9$} & $4 \cdot 6$ \\
\hline $\mathbf{S}_{2.3 .4 .6}$ & 6 & \multicolumn{2}{|c|}{$4 \cdot 6$} & $2 \cdot 3$ \\
\hline $\mathrm{S}_{3.4 .4 .6}$ & 5 & \multicolumn{2}{|c|}{$\begin{array}{l}0 \cdot 0 \\
2 \cdot 3\end{array}$} & 1.6 \\
\hline $\mathbf{S}_{2.2 .2 .6}$ & o & \multicolumn{2}{|c|}{$\begin{array}{l}2 \cdot 3 \\
0 \cdot 0\end{array}$} & $2 \cdot 3$ \\
\hline
\end{tabular}

\section{DOMINANCE IN THE POLLEN GRAIN}

It has been shown in the last section that $\mathbf{S} 4.6$ pollen grains are compatible in a style carrying $\mathbf{S}_{4}$ and lacking $\mathbf{S} 6$, hence the $\mathbf{S} 6$ allele overrides the effect of $\mathbf{S}_{4}$ in the pollen. The same pollen grain on a style carrying $\mathbf{S} 6$ and lacking $\mathbf{S}_{4}$ is incompatible. Thus the $\mathbf{S}_{4}$ allele does not interfere with the action of $\mathbf{S} 6$ in the pollen grain. In other words, the $\mathbf{S} 6$ allele has a dominating effect over $\mathbf{S}_{4}$, but before we can call this true dominance two other conditions must be satisfied.

(r) Heterogenic $\left(\mathbf{S}_{4} .6\right)$ pollen grains in a style carrying $\mathbf{S} 6$ and not $\mathbf{S}_{4}$ should have the same incompatibility reaction as the homogenic (S6.6) pollen grain in a style carrying both these alleles. For technical reasons it is impossible to determine whether pollentube growth differs in these two crosses, but no seeds are produced in either.

(2) $\mathrm{S}_{4} .6$ pollen grains should be compatible in a style carrying $\mathbf{S}_{4}$ and not $\mathbf{S} 6$ to the same extent as in a style carrying neither of these alleles. The mean seed production in these two cases respectively is $19 \cdot 6 \pm 8 \cdot 0$ and $16 \cdot 5 \pm 5 \cdot 7$ per flower pollinated. In no respect, 
therefore, is the evidence against the effect being true dominance, and in many ways there are decisive data in favour.

On similar evidence $\mathbf{S}_{2}$ is dominant over $\mathbf{S}_{3}$ in an $\mathbf{S}_{2.3}$ pollen grain and $\mathbf{S}_{3}$ is partially dominant over $\mathbf{S}_{4}$ in $\mathbf{S}_{3.4}$ pollen. The pollen $\mathbf{S}_{3} .6, \mathbf{S}_{2.6}$ and $\mathbf{S}_{2.4}$ fail to produce seed in all styles carrying one or the other of these alleles, hence these types do not show dominance. From the results in table 4 we know that there is competition between the alleles in $\mathbf{S}_{3} .6, \mathbf{S}_{2.6}$ and $\mathbf{S}_{3.4}$ pollen, which results in partial suppression of the action of both alleles.

These interactions in the different genotypes are summarised below :-

\begin{tabular}{|c|c|c|c|c|c|}
\hline $\begin{array}{c}\text { Pollen } \\
\text { genotype }\end{array}$ & Competition & Dominance & $\begin{array}{c}\text { Pollen } \\
\text { genotype }\end{array}$ & Competition & Dominance \\
\hline $\mathrm{S}_{3.6}$ & + & - & $\mathrm{S}_{4.6}$ & - & $\mathbf{S} 6$ \\
\hline S2.6 & + & - & S2.3 & - & $\mathbf{S}_{2}$ \\
\hline$S_{3 \cdot 4}$ & + & $S_{3}$ & $S_{2.4}$ & - & - \\
\hline
\end{tabular}

The question now arises as to what the three relationships, viz. dominance, competition and no interaction established between the four alleles, have with one another. The results show that the four alleles can be placed in a linear order to which fixed values are assigned as in fig. I.

We then find that (I) differences of ro or less between alleles on the same scale give competition; (2) differences between 15 and 30 give dominance of the higher over the lower in proportion to the difference ; (3) with a difference above 30 interaction ceases.

I have reason to believe that a linear order will not prove to be a sufficient specification of these alleles; it does, however, provide a frame of reference in the design of future experiments.

In diploid and tetraploid styles the $\mathbf{S}$ alleles are independent in their action. Thus the specific action of each allele in the style is confined to repelling pollen tubes carrying the same allele. In fact, the whole system of incompatibility in diploid plants depends upon the style inhibiting two kinds of pollen. If one allele were dominant in the style only one kind of pollen would be inhibited, and since the pollen reaction is determined by its own gametic constitution this would lead to self-compatibility. Since the incompatibility mechanism requires this independence of gene action in the diploid style it must have been brought about by natural selection. It is not surprising that such independence should persist in the tetraploid style.

In the haploid pollen grain, however, no such selection has been at work; the necessary environment of having two alleles in the same nucleus has not been present. It is to be expected, therefore, that $\mathbf{S}$ alleles in diploid pollen grains would show new interactions. 
The dominance relationship between some of these alleles in the diploid pollen grain must also be independent of selection. Clearly these alleles have dominance as a primary property of the gene.

It would be hazardous to infer that a similar property is present

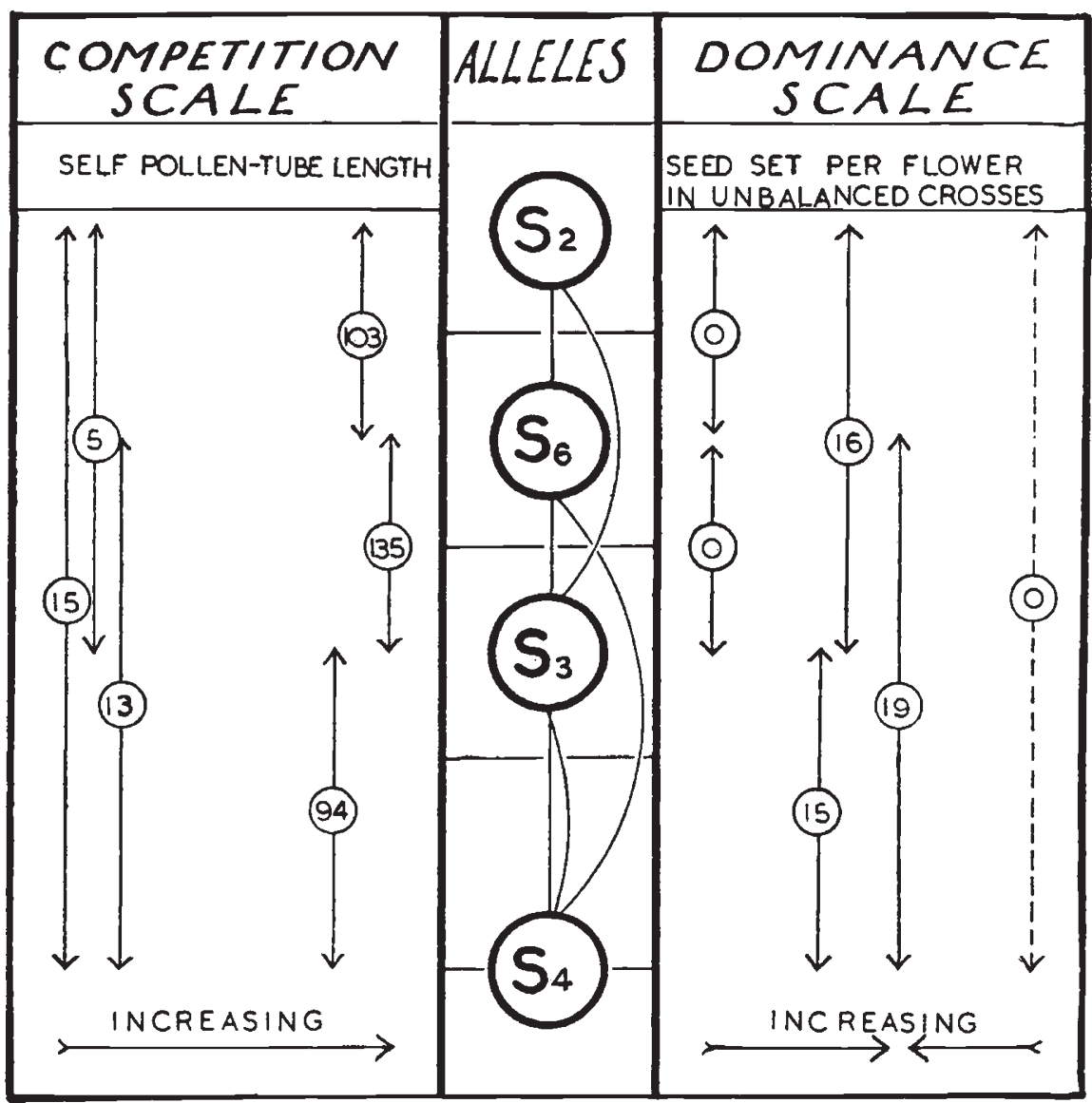

FIG. I.-The four $\mathbf{S}$ alleles arranged in linear order according to their interactions, viz. (I) Competition as measured by the growth of pollen tubes from heterogenic combinations of alleles in self-pollinations, and (2) dominance as measured by seed set in crosses where the lower (i.e. recessive) allele of a heterogenic combination is present in the female parent. Straight line joining the $\mathbf{S}$ alleles, competition; curved line, dominance of the higher over the lower.

Note.-Alleles close together on the scale, e.g. $\mathrm{S}_{2}$ and $\mathbf{S} 6$ show competition and no dominance, alleles further apart, e.g. $\mathbf{S} 6$ and $\mathbf{S}_{4}$ show dominance and no competition, alleles at an intermediate distance apart (e.g. $\mathbf{S}_{3}$ and $\left.\mathbf{S}_{4}\right)$ show dominance and competition, and alleles at the extremes of the scale show neither competition or dominance.

with other genes, because the incompatibility gene differs from these in a number of ways. The most important difference is probably that the $\mathbf{S}$ alleles are neomorphs, and most mutant alleles of ordinary genes are hypomorphs (Muller, 1933). Thus $\mathbf{S}$ alleles differ in their effects on the phenotype in a qualitative way; each allele produces a 
new "character." The normal allele and hypomorphic mutants of more ordinary genes produce similar effects on the phenotype but of different degree; the difference is here quantitative rather than qualitative.

Dominance in most genes is due to selection of the whole genotype as shown by Fisher (1930), but it seems improbable that it is due entirely to selection of the background genes since we have seen that genes can be dominant without selection having operated. Clearly chance differences between a wild type allele and a mutant can give complete dominance.

An effect similar to the competition between some of the $\mathbf{S}$ alleles has been found in Drosophila melanogaster by Dubinin (1929) and Agol (I93I) at the scute locus. In compounds of different scute alleles " the different types of the gene scute result in a partial reversion to the wild type, revealing only those characters which are common to both genes present in the compound, while characters specific of each mutation disappear" (Agol, I93I). In both the $\mathbf{S}$ gene in Oenothera and the scute gene in Drosophila the full expression of both alleles are mutually suppressed when two different alleles are present together.

The interesting point about this similarity is that the alleles of both the $\mathbf{S}$ gene and the scute gene are neomorphs to one another. It is clear that competition interaction can only be observed in neomorphs. For, if one allele is hypomorphic to the other, the compound is unlikely to have a lower expression than the hypomorph itself, since both alleles are acting towards the same character expression.

The cubitus interruptus gene in Drosophila melanogaster is an example of interaction between normal and hypomorphic alleles. Stern (1943) has shown that increasing doses of the ci allele leads towards normality of the character, but that a heterozygote ci+ is less normal than the hemizygote + , but more normal than the homozygote ci ci. Clearly the ci allele has competed with the wild-type allele so that the wild-type allele cannot gain its full expression, but because the two alleles are working towards the same end result, the total effect in the heterozygote is greater than the effect of two ci alleles.

These examples show that the interaction effects between two neomorphs are different from the interaction effects between a hypermorph and a hypomorph. The interaction may be similar but its expression is different.

\section{GENERAL PRINCIPLES}

The main effects of tetraploidy on incompatibility can now be stated.

I. Some pairs of different $\mathbf{S}$ alleles compete in diploid pollen grains. The interaction results in compatibility of the pollen grain in a style carrying both the alleles. This effect is partial in Oenothera organensis and complete in Petunia sp., Pyrus communis, Pyrus malus and Trifolium repens. 
2. Pairs of $\mathbf{S}$ alleles which do not show competition may show dominance of one allele over another in the pollen grain.

3. These two effects differ according to the species in their power to alter the incompatibility reaction.

With these three principles it is possible to explain the results in most species that have been adequately tested. An entirely different effect has been introduced, however, by Atwood (1944) to explain his results in tetraploid Trifolium repens, viz. "that growth of pollen bearing two different alleles depends sometimes on the interaction between the stigma and all pollen placed upon it rather than on a specific oppositional effect." Thus in Trifolium repens all diallelic plants are assumed to be self-incompatible because they produce only one type of heterogenic pollen grain; while triallelics and tetrallelic plants in virtue of their producing more than one type of heterogenic pollen are self-compatible. This principle is not applicable to Oenothera organensis, Pyrus species, or Petunia, since in Oenothera no plants are fully self-compatible and in Pyrus and Petunia diallelics are self-compatible.

Certain difficulties were encountered in the results on Trifolium, such as cross-incompatibility in one direction only, between the parents and the $F_{1}$ plants, which were assumed to be diallelic. An equally satisfactory fit to the results in Trifolium can be made with the three principles laid down above, but it is unprofitable to do this without first having an accurate knowledge of the tetraploid genotypes. This can only be obtained by a method which is independent of behaviour that is conditioned by tetraploidy. It would be most valuable to have these genotypes accurately determined by using haploid pollen of known constitution.

An interpretation can be made on the lines of the Oenothera results, that certain combinations of alleles compete in the pollen grain and are compatible and other combinations do not compete and are incompatible. In fact the results of self pollen-tube growth in Oenothera given in table 4 are strikingly similar to the results of selfpollination in Trifolium, if we make the assumption that competition, when it occurs, between different $\mathbf{S}$ alleles in pollen grains is enough to overcome incompatibility in Trifolium. Such an interpretation without introducing any new effects would explain the presence of self-incompatible diallelic plants and the self-compatibility of the triallelic and tetrallelic plants.

Evidence that different $\mathbf{S}$ alleles compete in the pollen to give compatibility has been found in three species, but evidence that, within a species, some combinations of $\mathbf{S}$ alleles compete in this way and other combinations do not, has been found only in Oenothera. There is good evidence, however, of a similar condition in Pyrus malus. By giving heat treatments to pollen-mother-cells a proportion of the pollen grains are diploid, and if this mixed pollen is applied to incompatible styles, seeds are produced giving triploid progeny (Lewis, I943b). 
Further results have shown a remarkable situation in apples. Apple varieties are of two kinds. Beauty of Bath and Northern Spy after treatment and self-pollination produce a high set of seeds which contain triploid embryos. Charles Ross and Lane's Prince Albert, on the other hand, although much diploid pollen was present, did not produce seed.

This is exactly the sort of effect which is to be expected on the Oenothera results. Varieties which give triploids contain pairs of $\mathbf{S}$ alleles that compete in the pollen. Varieties which do not give triploids contain $\mathbf{S}$ alleles that do not compete.

\section{SUMMARY}

I. Incompatibility alleles in general provide means for specific tests of gene interaction on a large scale by the study of pollen-tube growth and seed set. Further, in tetraploids the diploid pollen provides the means of studying the interaction of alleles which have never had to interact before, i.e. prior to selection.

2. Oenothera organensis has 45 alleles of the $\mathbf{S}$ gene, $\mathbf{S r . 2 . 3} \ldots$ each specific and absolute in preventing self-fertilisation in the diploid.

3. The plants produced from doubled Oenothera organensis are always diallelic, e.g. $\mathbf{S}_{2.2 .4 .4}$ or $\mathbf{S}_{3.3 .6 .6}$; their pollen is of two kinds, one-third homogenic, e.g. $\mathbf{S}_{2.2}, \mathbf{S}_{3.3}$ and two-thirds heterogenic, $\mathbf{S}_{2.4}, \mathbf{S}_{3} .6$.

4. S2.2.4.4 plants selfed all have short pollen tubes. Both types of pollen are equally inhibited.

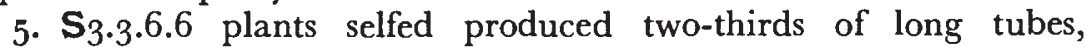
evidently $\mathbf{S}_{3}$ and $\mathbf{S} 6$ interact or compete to suppress their individual effects in the heterogenic pollen.

6. Of the alleles examined $\mathbf{S}_{2.6}, \mathbf{S}_{3} .6$ and $\mathbf{S}_{3.4}$ compete, and $\mathbf{S}_{2.3}, \mathbf{S}_{2.4}$ and $\mathbf{S}_{4} .6$ do not compete.

7. Diallelics intercrossed give not only diallelics, but also triallelics, e.g. $\mathbf{S}_{3 \cdot 4 \cdot 6.6}$ and tetrallelics, e.g. $\mathbf{S}_{2 \cdot 3 \cdot 4.6}$. These, when selfed, have all given some long tubes because, so far, they all have some pollen genotypes with competing alleles.

8. The long pollen tubes of triallelics never, those of tetrallelics rarely, achieve fertilisation.

9. Crosses between diallelics and between triallelics which are identical in respect of the $\mathbf{S}$ alleles give the same types of gene competition and consequently the same degree of pollen-tube growth and fertilisation as do the self-pollinations.

ı. In crosses where the male parent has two like or unlike alleles, which are not present in the female, seed is of course produced. But, for an unknown reason, more seed sets when the compatible pollen grains are homogenic for $\mathbf{S}$ than when they are heterogenic : the $\mathbf{S}$ heterogenic pollen grains are at a disadvantage in respect of general fertility. 
I I. Certain crosses between triallelics reveal the occurrence of an inherent dominance. An $\mathbf{S}_{4.6}$ pollen grain gives seed in an $\mathbf{S} 2.3 .4 .4$ style, but not in an $\mathbf{S}_{2.3 .6 .6}$ style. Thus $\mathbf{S} 6$ is dominant over $\mathbf{S} 4$ in a diploid pollen grain; similarly, in an $\mathbf{S}_{2} .3$ pollen grain, $\mathbf{S}_{2}$ is dominant over $\mathbf{S}_{3}$; in $\mathbf{S}_{3.4}$ pollen $\mathbf{S}_{3}$ is dominant. This dominance must be an unselected property of the gene since selection has never been operating in the diploid pollen.

I2. The known self-fertility of tetraploids and of unreduced pollen of self-incompatible species, particularly in Petunia, the apple and pear seem to be explained by the two methods of interaction, by competition and by dominance.

\section{APPENDIX}

\section{Terms}

Diallelic . . . Atwood (1944). A tetraploid plant with two different alleles.

Triallelic . . . Atwood (I944). A tetraploid plant with three different alleles.

Tetrallelic . . Atwood (I944). A tetraploid plant with four different alleles.

Heterogenic . . Fisher (unpublished). A gamete with different alleles.

Homogenic . . Fisher (unpublished). A gamete with the same alleles.

Balanced+ crosses . Those in which at least one of the pollen genotypes has neither of its two $\mathbf{S}$ alleles present in the female parent of the cross,

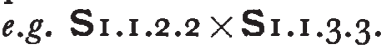

Balanced - crosses . Those in which all the pollen genotypes have both their $\mathbf{S}$ alleles present in the female parent, e.g. S I.1.2.2 $\times \mathbf{S}_{\text {I.1.2.2. }}$.

Unbalanced crosses . Those in which the only pollen genotypes, which have an $\mathbf{S}$ allele not present in the female parent, are those which have one $\mathbf{S}$ allele that is present and one that is not present in the female, e.g. Si.I.2.2 $\times$ Si.I.2.3.

\section{Symbols}

I. The traditional way of denoting the genetic constitution of a plant in respect of the incompatibility (S) genes as $\mathbf{S}_{x} \mathbf{S}_{y}$ has been shortened to Sx.y.

2. It is necessary with diploid pollen grains to be able to denote the relationship between the two $\mathbf{S}$ alleles in the pollen and the $\mathbf{S}$ alleles in the style of a particular cross. When an allele is common to the pollen and style the suffix is in bold-face type, thus an Sx.y. pollen grain on an Sx.x.z.z. style is denoted as Sx.y. 


\section{REFERENCES}

Agol, I. J. . . . . . . . . . 1931. Genetics, 16, 254.

Atwood, S. S. . . . . . . . 1944. Proc. Nat. Acad. Sci., 3o, 69.

Crane, M. B. . . . . . . . 1923. J. Pomology, 3,67 .

Crane, M. B., and Lawrence, I929. Ibid., $7,276$. W. J. C.

Crane, M. B., and Lewis, D. . . 1942. 7. Genet., 43, 3 I.

Crane, M. B., and Thomas, P. T. . 1939. Ibid., 37, 287.

DARLington, C. D. . . . . . . I928. Ibid., 19, 213.

Dubinin, N. P. . . . . . . . 1929. Biol. Zbl., 49, 328.

EMerson, S. . . . . . . . 1938. Genetics, 23, 190.

Fisher, R. A. . . . . . . . 1930. The Genetical Theory of Natural Selection. Oxford.

Gairdner, A. E. . . . . . . 1926. 7. Genet., 16, 341.

Hechт, A. . . . . . . . . 1944. Genetics, 29, 69.

Lawrence, W. J. C. . . . . . 1930. Genetica, 12, 269.

Levan, A. . . . . . . . . . . 1936. Hereditas, 22, 278.

Lewis, D. . . . . . . . . . 1942. Proc. Roy. Soc., B., 16, 288.

". . . . . . . . 1943a. F. Genet., 45, г 71.

" . . . . . . . 1943b. Ibid., 45, 261.

Lewis, D., ANd Modlibowska, I. . 1942. Ibid., 43, 211.

Livermore, J. R., and Johnstone, 1939. Amer. Pot. Fourn., 17, 170.

F. E.

Mather,K. . . . . . . . 1943. F. Genet., 45, 215.

MATHER, K., AND DE Winton, D. $\quad \cdot \quad$ 1941. Annals of Botany, 5, 297.

Modlibowska, I. . . . . . . 1945. F. Pomology, 21, 24.

Muller, H. J. . . . . . . 1933. Proc. Sixth Internat. General Congress, 1, 213.

Sansome, F. W., and Philp, J. . . 1932. Recent Advances in Plant Genetics. London.

Stern, C. . . . . . . . . 1943. Genetics, 28, 44I.

Stout, A. B., and Chandler, C. . 1941. Science, 94, 118.

" " $" \quad . \quad 1942 . \quad$ Ibid., $96,257$.

Upcott, M., ANd Philp, J. . . . 1939. 7. Genet., 38, 91 .

Williams, R. D., And Silow, R. A. I933. F. Genet., 27, $34^{1}$. 